\title{
RATZEL E A GEOPOLÍTICA DAS POTENCIALIDADES
}

\section{Ratzel and the potentialities Geopolitics}

\section{Ratzel y la Geopolítica de las potencialidades}

\author{
Wendell Teles de Lima \\ Doutor em Geografia; Prof. da Universidade do Estado do Amazonas \\ wendelltelesdelima@gmail.com \\ Ana Maria Libório de Oliveira \\ Mestra em Estudos Amazônicos; Profa. do Instituto Federal de Brasília \\ analiborio@gmail.com \\ Iatiçara Oliveira da Silva \\ Doutoranda em Educação Ambiental na Universidade do Mato Grosso \\ iaticara@gmail.com \\ Sebastião Perez de Souza \\ Especialista em Libras; Prof. da Secretaria de Educação do Amazonas \\ perezsouza1810@gmail.com
}

Artigo enviado para publicação em 11/12/2019 e aceito em 14/05/2020

DOI: $10.12957 /$ tamoios.2020.47242

\section{Resumo}

A Geopolítica é um importante campo de estudo que após a Segunda Guerra foi negligenciado. Só a partir dos anos de 1970 voltou a ter atenção de vários autores de diversas ciências. A retomada desse conhecimento começa com as críticas à Friedrich Ratzel e vários autores que proclamavam a importância do Estado, do território e da nação como elementos fundamentais de poder. O geógrafo alemão contribuiu para a constituição da geopolítica e seus elementos estruturadores, saindo do viés naturalizante de sua época e, tendo como ponto de vista a preocupação com poder, potencialidades existentes no território e as projeções dos Estados. Os recursos físicos foram fundamentais na constituição do poder nos Estados e no desenvolvimento das teorias expansionista. Este artigo teve como objetivo apresentar como a configuração territorial e, seus elementos naturais ainda são pertinentes na análise do território para a geopolítica, tendo a pesquisa bibliográfica indicando a importância dessa análise. $\mathrm{O}$ desenvolvimento dessa pesquisa ocorreu em função de demonstrar que a análise geopolítica é importante para a compreensão dos territórios estatais que é nosso foco. Objetivando pontuar a importância da configuração geográfica, dos elementos naturais dos territórios e da longevidade das ideias ratzelianas fundamentais atualmente e na geopolítica.

Palavras-chaves: Estado; Geopolítico; Potencialidades; Recursos.

\section{Abstract}

Geopolitics is an important field of study that was neglected after World War II. Only from the 1970s did he return to the attention of several authors from different sciences. 
The recovery of this knowledge begins with criticisms of Friedrich Ratzel and several authors who proclaimed the importance of the State, territory, and nation as fundamental elements of power. The German geographer was great taxpayer for constitution of the space analysis and your elements formatters, leaving the naturalizing bias of its time and, having as point of view the preoccupation with can, existing potentialities in the territory and the State projections. The physical resources were fundamental in the power constitution in the State and in the theories geopoliticses development. This article had as goal present as if it finds in the current days the territorial configuration and, their natural elements still are pertinent in the territory analysis for the geopolitics, having the bibliographical research indicating the importance of this analysis. The development of this research occurred in function of demonstrating that the analysis geopolitics is important for the territories state owned companies comprehension that is our focus. Objectifying punctuate the importance of the geographical configuration, of the natural elements in the forms projective of the territories and of ideias ratzelianas longevity fundamental in the current days and in the geopolitics.

Keywords: State; Geopolitical; Potentials; Resources.

\section{Resumen}

La geopolítica es un importante campo de estudio que fue descuidado después de la Segunda Guerra Mundial. Solo a partir de la década de 1970 volvió a llamar la atención de varios autores de diferentes ciencias. La recuperación de este conocimiento comienza con las críticas a Friedrich Ratzel y varios autores que proclamaron la importancia del Estado, el territorio y la nación como elementos fundamentales del poder. El geógrafo alemán fue un gran contribuyente para la constitución del análisis espacial y sus elementos estructuradores, saliendo del sesgo naturalizante de su época y, teniendo como punto de vista la preocupación con poder, potencialidades existentes en el territorio y las proyecciones de los Estados. Los recursos físicos fueron fundamentales en la constitución del poder en los Estados y en el desarrollo de las teorías geopolíticas. Este artículo tuvo como objetivo presentar como se encuentra en los días actuales la configuración territorial y, sus elementos naturales todavía son pertinentes en el análisis del territorio para la geopolítica, teniendo la investigación bibliográfica indicando la importancia de ese análisis. El desarrollo de esta investigación se produjo en función de demostrar que el análisis geopolítico es importante para la comprensión de los territorios estatales que es nuestro foco. Objetivando puntuar la importancia de la configuración geográfica, de los elementos naturales en las formas proyectivas de los territorios y de la longevidad de las ideas ratzelianas fundamentales en los días actuales y en la geopolítica.

Palabras claves: Estado; geopolítico; potencial; recursos. 


\section{Introdução}

As análises relacionadas ao poder surgem em 1897 na obra geografia política com Friedrich Ratzel e com o pivô Geográfico da História da Conferência Geográfica inglesa de autoria de Halford Mackinder (1861-1947). Apesar deste nunca ter usado a palavra geopolítica e, tendo começado toda uma tradição e preocupação nesse sentido, cabia ao jurista sueco Rudolf Kjellén (1864-1922) sistematizar esse ramo do conhecimento de inspiração ratzeliana.

Em ambos os casos, as preocupações eram com a relação de poder, território e potencialidade, elas ocorreram por meio dos recursos existentes no território como a existência e importância dos elementos naturais que será a marca da geografia tradicional e fortalecida pela geopolítica no início do Século XX.

Para entender esse contexto e sua importância na atual conjuntura uma pesquisa bibliográfica serviu como respaldo, demonstrando a importância estruturante desse elemento que compõem em graus os territórios e que, chega a ser decisivo em políticas territoriais termo utilizado por Ratzel ao longo do tempo, até hoje utilizado e bem conhecido no mundo.

Apesar do processo ser naturalizante, ou seja, os elementos naturais são importantes para o desenvolvimento de qualquer país, as pesquisas sobre geopolítica ligada ao pragmatismo e, ao mesmo tempo, realista servem com respaldo para explicação dos Estados.

Em função de uma crítica social nos ramos das ciências humanas e sua separação das ciências naturais de formas abrupta criou-se um radicalismo estreito respigando de forma direta na geografia política e geopolítica sobre a importância desses elementos que constituem os territórios. Sendo necessário seu resgaste e demonstração para uma análise atual que requer entender os princípios ratzelianos para compreensão da ação dos próprios Estados.

\section{Metodologia}

No desenvolvimento dessa pesquisa ocorreu a utilização de artigos em revista científicas, livros, teses com a preocupação que permeou em torno de subsidiar a inquietação com a configuração geográfica direcionada aos elementos naturais, portanto, demonstrando como esses elementos muitas vezes colocados determinantes e naturalistas são importantes na busca e nas projeções dos Estado.

A ideia do meio geográfico relacionado a análise ratzeliana ainda é uma fonte de leitura importante para entender a trama e nas pretensões geográficas, ou seja, a necessidade de superação de uma ideia equivocada e permanente que termina escamoteando a função dessas estruturas territoriais e que fazem na realidade parte das ações geopolíticas, assim como, as projeções possíveis como um recurso para os Estados.

Portanto a interpretação será feita pelo realismo e ter-se-á como premissa norteadora a seguinte ideia "O elemento fundador, formador do Estado, foi o enraizamento no solo de comunidades que exploraram as potencialidades territoriais". (RAFFESTIN, 1993, p. 13)

\section{Resultados e Discussões}

A geopolítica teve como origem expansionismo na realidade seu nascimento original ocorre no estado sueco com o jurista cientista político Rudolf Kjellén 1905, 
entretanto, observa-se a utilização desse termo em 1899, com o trabalho referente as fronteiras da Suécia. O surgimento ou o ambiente para esse cenário ocorreu em função do Século XVIII, a Suécia constituiu-se a principal potência do Norte europeu antes de sua fragmentação territorial e a ascensão da Rússia e Prússia.

A inspiração na obra "Politische Geographie" ou Geografia Política de 1897 de Friedrich Ratzel e as preocupações estavam em torno do espaço vital. Aspiração de uma grande potência traz a inspiração para os planos das potências hegemônicas diante de seus planos de liderança europeia na busca de uma posição mundial

\begin{abstract}
A receptividade ao discurso imperialista/conservador/autoritário e ao neologismo de Kjellén foi bastante significativa, não só na Suécia, como entre o público de língua alemã (Alemanha e Áustria). Por isso, as ideias de Kjellén rapidamente se tornaram populares no espaço cultural germânico, onde o geologismo foi introduzido, tal como os seus trabalhos, pelo geógrafo austríaco Robert Sieger nos primeiros anos do século XX. (Korinman, 1990: 349, nota 79). Esta rápida germanização da Geopolítica deveu-se também ao facto do sueco Kjellén ter uma profunda admiração pela Alemanha imperial e constituir, juntamente com o britânico Houston Stewart Chamberlain e o francês Joseph-Arthur, conde de Gobineau, «um famosíssimo trio não alemão super germanófilo» (WEIGERT, 1942, p. 275 apud FERNANDES, 2002. p. 2-3)
\end{abstract}

Tendo em vista as inspirações mais voltadas para o lado projetivo em ressaltar a posição de destaque e que essas ideias poderiam trazer para os germanólogos uma inspiração no fortalecimento e pretensões espaciais, tendo em vista o papel destaque a ser alcançado pela Alemanha na Europa e no mundo, resultando diretamente no conflito e posições no cenário Europeu.

A necessidade de um projeto alemão destina-se em consideração as características de que a indigência e pretensões de cada país deve-se ter seu desenvolvimento na geopolítica, aliás, serão muitas as escolas geopolíticas e suas nuanças diante do seu desenvolvimento e pretensões em cada território.

Os grandes problemas relacionados a esse pensador é sua língua que pouco foi entendida ou compreendida na maioria das vezes no mundo, daí as dificuldades de interpretação.

Por um lado, a tradução seletiva e parcial da obra de Ratzel para outras línguas resultou em interpretações errôneas e citações fora do contexto. Poucas publicações da vasta produção ratzeliana foram traduzidas para outras línguas - talvez devido à dificuldade de realizar traduções adequadas e corretas dos textos originais em alemão.

A Geopolítica passou a ser não bem vista pelas interpretações ocorridas pelo mundo e da própria escola francesa.

As escolas geopolíticas vão variar de acordo com pretensões, como dito até aqui, em função dos projetos nacionais, ao mesmo tempo, a relação com o poder e a hegemonia depende da escala de pretensões e que varia de acordo com as projeções dos Estados, mas o pragmatismo é característica fundamental. Para o geopolítico Spykman apud Binimelis (2006) ela apresenta em três formas.

Definitivamente, o que é geopolítica? O que está atrás dos discursos geopolíticos? Onde surgiu? E como tem encontrado espaço entre os atores políticos, sociais, intelectuais e, especialmente, militares? Nicholas Spykman atribui-lhe três diferentes significados gerais: a) associando-a primeiramente a escola histórico-filosófica do III Reich quando buscava legitimar a edificação de um Estado colocando a força a serviço de sua expansão; b) a geopolítica como sinônimo de geografia política; e c) o estudo e planejamento de uma política de segurança que não se pode considerar 
independente das características da região em que se manifestam as tensões. (BINIMELIS, 2006, p. 2).

Foi com Karl Haushofer que a geopolítica ganhou força dentro da sua popularização com a revista Zeitschrift für Geopolitik ou jornal da Geopolítica que para época, as tiragens eram expressivas para a popularização do mundo sobre o assunto relacionado a esse conhecimento, chegando até repercussão internacional e até mesmo participação em artigo do teórico brasileiro Everardo Backheuser conhecido nos anos 20 e 30 com esse tipo de preocupação de maneira mais pragmático.

O pensamento de Everardo Adolpho Backheuser deve ser entendido como fruto de sua época. As preocupações geopolíticas diante do território brasileiro são partes integrantes de suas análises através dos múltiplos enfoques diante das preocupações relacionadas a melhor forma de organização do território, servindo de base para estudos posteriores de outros pensadores geopolíticos.

Backheuser atuou ao longo de sua carreira como engenheiro, geólogo, escritor, deputado estadual e pedagogo. Foi cátedra de geopolítica na Escola Politécnica da Universidade Federal do Rio de Janeiro.

Os temas trabalhados pelo geopolítico giravam em torno da centralização política, coesão territorial, anulação do regionalismo, dentre outros. A organicidade, a concepção advinda da fisiologia e pragmatismo são seus guias nas interpretações metodológicas que permeiam suas obras. (LIMA et al., 2017 p.1-2).

Backheuser através de sua análise pragmática baseada numa perspectiva estatal tendo como elemento o autoritarismo de uma visão estatal e, ao mesmo tempo, condicionada aos elementos que compõem o território, entretanto, tendo em mente que esses elementos são fontes do sucesso das políticas territoriais. Para Lima (2015), por exemplo, os sistemas geográficos constituem-se por meio dos elementos no território e são potencializados pelo Estado ou atores.

Esses elementos são decisivos e potencializados pelos estados, portanto, a configuração territorial nos conjuntos de elementos existentes tem em vista as próteses territoriais e não o formato do território. Mas para Lima $(2015)^{2}$ de acordo com este autor o sistema geográfico abrange mais que isso, em função das ações projetivos do Estado e que seus interesses no território são de construir as relações de poder e de fazer acordos com os elementos potencializadores e, que dependendo da constituição desse espaço podem ter a predominância de elementos naturais.

Ratzel abordava a preocupação da seguinte forma:

Como o Estado não é concebível sem território e sem fronteiras, constituiu-se bastante rápida- mente uma geografia política, e ainda que nas ciências políticas em geral se tenha perdido de vista com frequência a importância do fator espacial, da situação, etc., considera-se, entretanto como fora de dúvida que o Estado não pode existir sem um solo. Abstraí-lo numa teoria do Estado é uma tentativa vã que nunca pôde ter êxito senão de modo passageiro. Pelo contrário, tem havido muitas teorias da sociedade que permaneceram completamente alheia a quaisquer considerações geográficas; estas têm mesmo tão pouco lugar na sociologia moderna que é inteiramente excepcional se encontrar uma obra em que elas desempenham algum papel. A maior parte dos sociólogos estuda o homem como se ele se tivesse formado no ar, sem laços com a terra. O erro dessa concepção salta aos olhos, é verdade, no que concerne às formas inferiores da sociedade, porque sua extrema simplicidade faz com que sejam semelhantes às formas mais elementares do Estado. Mas então, se os tipos mais simples de Estado são irrepresentáveis sem um solei que lhes pertença, assim também deve ser com 
os tipos mais simples de sociedade; a conclusão se impõe. (RATZEL, 2012, p. 93)

Tendo em vista as recomendações do eminente geógrafo alemão, pai da análise espacial, em sua compreensão estatal atenta-se o seguinte quesito, de que o Estado para ser analisado em seu próprio desenvolvimento ou existência deve ser levado em consideração os elementos geográficos, tais como: fronteiras, extensão, localização e o solo.

Pensando na perspectiva ratzeliana, o solo foi considerado um fruto importante no desenvolvimento dos estados e é o espaço vital, sendo fruto dessas preocupações, em que a constituição que Santos (1988) vai denominar de configuração geográfica e que, no entanto, não se restringirá aos aspectos naturais existentes no território, mas sim, a próteses territoriais, ou seja, a uma natureza modificada que termina misturando-se com a mesma e se tornando território.

Ao mesmo tempo, Ratzel (2011) ressalta que sem levar em consideração esses elementos existentes na composição em qualquer análise, como tentou algumas abordagens, até mesmo ditas modernas, ela será incompleta tendo em vista que esses elementos são partes constituinte para uma compreensão integral do próprio espaço.

Conforme Karol (2003),

Para Brezezinscki (1986, p. 10), geopolítico reflete a combinações de fatores geográficos e políticos que determinam a condição de um Estado ou região, enfatizando. $\mathrm{O}$ impacto da Geografia sobre a política. Guardadas as diferenças e as divergências que as definições que as definições suscitam e os momentos geográficos que foram elaboradas, chama atenção a importância do Estado em todas elas, mas não se verifica o tratamento de crescimento do capital, importante também é caráter espacial da Geopolítica, muitas vezes expostos com o poder sobre o território e os recursos. (KAROL, 2003, p. 19)

Para o cientista político, geopolítico e estadista americano Brezezinsck os elementos naturais na formação dos territórios são partes componentes de manobra geopolítica. Portanto, pensar um campo de ação sem esses elementos, como já dito até mesmo em teorias pós-modernas e recorrer ao naturalismo dá-se importância da constituição do espaço, assim como, renuncia ao próprio conhecimento geopolítico adotado pela ação do Estado e de grandes atores territoriais.

Pois, somente os próprios conseguem uma ação direcionada e desejada em função do seu poder econômico, por meio de grandes empresas nacionais e internacionais ou entidades com recursos altos.

Ratzel apud Geraldino (2014) aponta que o meio é fundamental na análise geográfica, apesar do momento atual onde se repercute a globalização e os fluxos virtuais, em que ambos são importantes para a análise global, no afã de desenvolver a geografia e, ao mesmo tempo, da geopolítica ter sido ao longo de sua história dita como determinista, naturalista nas questões ligadas a composição do território, na análise territorial que foi esquecida ao longo do tempo.

A sucessão de fatos e a relação proposital de impregnar a geografia e geopolítica com o imperialismo resultaram em uma restrição, como já dito, apenas como determinismo para provocar um esvaziamento na análise espacial, deixando os elementos de composição do território como apenas um objeto sem valor e importância em qualquer ponto estratégico do espaço e que passaria como receptáculo, seja para os efeitos da sociedade, para a atividade econômica e qualquer tipo de fluxo.

Geraldino (2014) reflete a seguinte questão 
Embora se mostrando rigoroso na delimitação dos fenômenos objetivos aos quais os geógrafos deveriam se ater, Ratzel não deixou evidente em sua Antropogeografia o mesmo cuidado em delimitar e definir conceitos como natureza, meio, ambiente, território e vários outros conceitos relativos a tudo que se faz como alteridade do ser humano, ou seja, tudo o que existe e que não é o próprio homem. Assim, apesar de parecer recorrentemente em seus escritos, o conceito de meio não assume um rigor de ordem formal. Ou seja, a terminologia meio em Ratzel não é preservada plenamente, sendo por diversas vezes sinonimada por outras formas conceituais como território, solo e natureza. Entretanto, nem por isso, poderíamos deixar de considerar que o meio ao qual fala Ratzel se faz como um conceito fundamental para compreendermos o pensamento desse geógrafo por, sobretudo, trazer um conteúdo rico o bastante para embasar grandes geógrafos posteriores. Notadamente, o meio ratzeliano, além dos atributos físicos e biológicos, é composto também de elementos de ordem humana. (GERALDINO, 2014, p. 126)

Ratzel e a geopolítica constituem elementos que formam o realismo geográfico onde a existência dessas configurações territoriais ainda são decisivas, mesmo em áreas consideradas menos dependentes dos recursos naturais tendo em vista que são componentes espaciais partes da estrutura condicionantes do território.

As preocupações diante de uma perspectiva aliada a uma geopolítica em algumas partes do mundo como em Portugal, através da concepção do realismo pragmático no momento contemporâneo, surge por exemplo com a preocupação da Escola Central de Oficiais e relaciona a Escolar Militar de Portugal e a Escola Central de Oficiais pelo Instituto de Altos Estudos Militares de Portugal estabelecendo ou demonstrando os principais fatores geopolíticos, conforme o Quadro 1 abaixo.

Quadro 1 - Fatores Geopolíticos (modelo IAEM)

\begin{tabular}{|c|c|c|}
\hline & & Extensão (dimensão e superfície) \\
\hline & & Localização (Posição relativa) \\
\hline & & Configuração (forma e fronteiras) \\
\hline Fator Físico & & Morfologia (relevo e hidrografia) \\
\hline & & Solo (natureza geológica do solo) \\
\hline & & Vegetação \\
\hline & & Clima \\
\hline & & Mar e vias navegáveis \\
\hline & $\begin{array}{l}\text { Demografia (aspectos } \\
\text { quantitativos) }\end{array}$ & $\begin{array}{l}\text { Efetivo populacional Distribuição e } \\
\text { densidade } \\
\text { Composição ou estrutura da população }\end{array}$ \\
\hline $\begin{array}{l}\text { Fator Humano } \\
\text { (população) }\end{array}$ & $\begin{array}{l}\text { Etnografia } \quad \text { (aspectos } \\
\text { qualitativos) }\end{array}$ & $\begin{array}{llr}\text { Características étnicas, linguísticas } & \text { e } \\
\text { religiosas } & \text { Homogeneidade } & \text { ou } \\
\text { heterogeneidade } & & \\
\text { Outros aspectos sociais } & \end{array}$ \\
\hline Fator Recursos Natura & & $\begin{array}{l}\text { Energéticos } \\
\text { Minerais } \\
\text { Alimentares }\end{array}$ \\
\hline Fator Circulação & & $\begin{array}{l}\text { Comunicações (transportes) Comunicações } \\
\text { (relações exteriores) }\end{array}$ \\
\hline Fator Tecnológico & & $\begin{array}{l}\text { Grau de desenvolvimento científico- } \\
\text { tecnológico }\end{array}$ \\
\hline Fator Estrutural & & $\begin{array}{l}\text { Aspectos Políticos Aspectos Econômicos } \\
\text { Aspectos Sociais Aspectos Militares }\end{array}$ \\
\hline
\end{tabular}

Fonte: Gonçalves (2011) 
No levantamento do quadro 1, demonstra-se o levantamento de como os elementos geográficos são partes da composição do poder geopolítico somado com os fatores humanos partes integrantes do levantamento territorial e surgem como potencial básico para ação dos Estados e suas ações projetivas.

Apesar de negar os elementos constituintes do território como a configuração territorial, Ratzel continua tendo sua importância estratégica na compreensão das relações de poder. Johan Rudolf Kjellén e Karl Ernst Haushofer que observaram a seriedade desse conhecimento, portanto, uma geopolítica instrumentalizada importante para pretensões e interesses de cada Estado.

\begin{abstract}
Ratzel está profundamente envolvido nos debates sobre o lugar da Alemanha no mundo. É membro fundador do Kolonialverein (Comité Colonial) e defende a ideia de um império colonial alemão. Trabalha sobre a África e estabelece um mapa deste continente, ainda mal conhecido no final do século XIX e vigorosamente disputado pelas potências europeias, ávidas de territórios e de mercados. Ao mesmo tempo, Ratzel constrói uma obra teórica de notável erudição: Studien über Polilische Raüme (Estudo sobre os Espaços Políticos), em 1895; Der Staat und sein Boden (Estado e Solo), em 1896; e sobretudo Politische Geographie [Geografia Política - uma geografia dos estados, do comércio e da guerra), em 1897. Em 1898, Ratzel publica Deutschland, Einfürhung in die Heimatkunde (Alemanha - introdução a uma ciência do país natal). Este livro, que teve um eco duradouro na opinião alemã até à Segunda Guerra Mundial, ilustra o aspecto extremo e sem dúvida o equívoco da ambição de Ratzel: apreender de maneira "científica" o seu próprio país e identificar as "leis objectivas" do 5 seu desenvolvimento geográfico. Onde acaba a ciência? Onde começa a paixão? (DEFARGES, 2003, p. 69 apud ARCASSA, 2011, p. 103)
\end{abstract}

A figura contraditória e, muitas vezes pouca compreendida graças a escola francesa,_continuará em suas análises em função do tempo vivido e, ao mesmo tempo, das suas interpretações.

Entretanto, ele foi um dos pioneiros da geografia moderna, seu papel foi fundamental na relação entre poder e na constituição dos territórios, para além da figura de um naturalista que trouxe os elementos constituintes do território como algo essencial no estabelecimento de poder e a utilização inicial feita pelos Estados.

Renegar a configuração da composição dos territórios e, ao mesmo tempo, menosprezar a importância de uma geopolítica que em suas ações ainda constitui em um realismo pragmático em que os elementos naturais e sua leitura, como fez Ratzel, foi fundamental na emergência de grandes potências e, ao mesmo tempo, diante de projeções.

A grande carga naturalista, crítica exacerbada sobre as teorias ratzelinas e, além disso, o desprestígio sobre as relações de poder, a propagação ou radicalismo dos discípulos do geógrafo germânico, como diante de Ellen Churchill Semple, suas ideias caracterizaram a geopolítica e a geografia política, do mesmo modo, foi prejudicial para o entendimento da compreensão das análises territoriais, o espaço passou ser pensada como elemento que abriga a sociedade e mesmo tempo como algo inerte que apenas é um palco de sustentação de qualquer tipo de fenômeno social tendo em vista que os demais elementos viraram partes secundárias.

Como foi ressaltado, pode se compreender melhor a obra de Ratzel quando se considera o momento histórico em que viveu, numa Alemanha recémunificada, enquanto a Inglaterra, a França e a Rússia e os Estados Unidos já haviam colonizado boa parte do mundo. Ratzel acreditava que a França e a Inglaterra tenderiam ao esfacelamento, em virtude, de que seus domínios 
estavam distribuídos por países descontínuos pelo mundo e culturalmente heterogêneos. Contudo, a Rússia e os Estados Unidos seriam mais sólidos, por conta da dominância numérica e cultural de um povo. Para Ratzel a solução para o incipiente estado alemão, era expandir-se para o leste e o sul, já que a Áustria germânica foi vencida pela Prússia e, para o oeste onde o declínio de Napoleão II, poderia ser encarado como um agouro de decaimento. Nesse sentido a obra de Ratzel expressa em seus dois livros mais famosos Antropogeografia e a Geografia Política demonstram a grande influência que esse autor teve para o desenvolvimento da Geografia, em especial, no que diz respeito ao papel do homem explicitando o papel político da Geografia. (MORMUL; ROCH, 2013 p. 3)

Conforme Mormul e Roch (2013), Ratzel trouxe os elementos mais convenientes na leitura do território tendo como ponto de partida o projeto político alemão, portanto, uma geografia de conveniências para a justificativa do projeto expansionismo, resultando na ideia de uma leitura geográfica distorcida.

Apesar dessa constatação radicalizada dos dois autores, no desenvolvimento em si de uma leitura mais política e as relações de poder, o que se observou foi que a supressão desses elementos como a natureza resultou em uma grande perda da leitura e de elementos importantes para uma construção mais crítica sobre os acontecimentos.

As críticas direcionadas a Ratzel e Geopolítica enfraqueceram entendimento das relações de poder e, igualmente, enfraquecendo dois ramos do conhecimento fundamentais para o entendimento da construção das relações de poder.

Compreender a formação dos territórios e condicionantes do contexto existente requer uma necessidade básica de resgatar e reconhecer os elementos constituintes do território como os elementos físicos que em muitos casos são fundamentais para uma análise geográfica política e de projeção de poder como no caso de interpretação geopolítica.

Para Barbosa e Costa (2000) a Geografia Política é fundamental na compreensão poder no mundo, que

No terceiro eixo estabelece um diálogo entre os geógrafos políticos Ratzel, Vallaux, Brunhes, La Blache, entre outros, passando pelas publicações mais recentes como as de Sanguin, Lacoste, Vesentini, Claval, Santos, Raffestin, Becker; com o intuito de discernir o papel que a Geopolítica desempenha no atual cenário de relações político-econômicas mundializadas (BARBOSA; COSTA, 2000)

Ou seja, a geopolítica aparece como um problema mundial que foi observado por Ratzel e ao longo do tempo por todos geógrafos demostrando a sua importância na compreensão do espaço geográfico.

\section{Conclusão}

O determinismo geográfico foi uma ideologia que vigorou o processo de construção geográfica e que teve como expoente maior a Escola de geografia alemã, entretanto, em seu desenvolvimento trouxe sempre a temática da importância das discussões da importância na configuração geográfica.

Apesar do estereótipo de naturalista referente a importância dos recursos na constituição dos territórios, essa temática sofreu importante nuanças com a análise ratzeliana e que levou em consideração a potencialidade desses recursos e seus usos dando uma conotação política. 
Pensar que as ideias de Ratzel foram naturalizante é pensar de forma equivocada, a importância dessa análise dentro da perspectiva da relação do poder e espaço introduz por esse teórico, tendo em vista de forma anterior, que eram vistas de forma simplistas.

Portanto, o espaço nessa concepção passa de ser apenas um receptáculo, ou mesmo, apensas onde ocorrem ações condicionadas pela sociedade já que essa mesma terminava sendo a parte dessa estrutura de existência.

As disputas estatais deram a construção de discursos particularizados ou de escolas nacionais ou forma de ler o espaço e compreender os fenômenos, assim como, o seu processo de despolitização da geografia, pela linha francesa e que repercutiu de forma direta na desconsideração da importância ou muitas desconsideração de alguns elementos que constituem a configuração e, que formaram os territórios, sobretudo os elementos naturais tão fundamentais na formação dos territórios e projetos de poder dos Estados.

A necessidade de um resgaste da análise sobre a importância da constituição do espaço ainda é premente, em função do estereótipo ao longo do tempo e em torno do debate da leitura do espaço e, como foi feita a imagem do conhecimento geopolítico realista em nome de uma leitura mais crítica que levam em consideração a potencialização do poder nos espaços territoriais.

\section{Referências}

BORBASA, Altiva; COSTA, Wanderley Messias. Geografia Política e Geopolítica. Boletim Paulista de Geografia, $n^{\circ}$ 71, 2000.

BINIMELIS, Cecilia Quintana. Sobre as Origens da Geopolítica Alemã. Intellector, Rio de Janeiro, Ano II, Volume III, N 5, julho/dezembro, p. 01-20. 2006.

FERNANDES, José Pedro Teixeira. Da geopolítica clássica à Geopolítica pós-moderna: entre a ruptura e a continuidade, Geografia (Londrina), p. 162-186, outono. 2002.

GERALDINO, Carlos Francisco Gerencsez. Sobre as Determinações do Meio no Discurso Geográfico. RAEGA - O Espaço Geográfico em Análise, Ra ${ }^{e e}$ Ga Curitiba, V. 31, p. 117-146, ago/2014.

GONÇALVES, Carlos Manuel Chaves. Geopolítica: um método auxiliar para a compreensão do mundo contemporâneo. A geopolítica dos Bálcãs. 2011. Dissertação Universidade Técnica de Lisboa, Instituto Superior de Ciências Sociais e Políticas, Lisboa (UTL). Lisboa - PT.

KAROL, Eduardo. Geografia Política e Geopolítica do Brasil (1982 - 2012). 2013. Tese (Doutorado em Geografia Humana) - Pós-Graduação em Geografia Humana, USP, São Paulo - SP.

LIMA, Wendell Teles de. Geopolítica Brasileira, O Papel de Mário Travassos e as Implicações na Constituição do Sistema Geográfico no Eixo de Integração e Desenvolvimento Manaus/ Caribe. 2015. Tese (Doutorado em Geografia) - Programa de Pós-Graduação em Geografia, UFPR, Curitiba - PR. 
LIMA, Wendell Teles de; OLIVEIRA, Ana Maria Libório de; SILVA, Iatiçara Oliveira da; BRAU, Deloni de Meira Freitas. A Geopolítica de Everardo Backheuser para o Brasil entre Processos e Retrocessos. Revista Geopolítica Transfronteiriça, V. 1, N. 1, p. 51-62, jul. 2017.

MORMUL, Najla Mehanna; ROCH, Márcio Mendes. Breves considerações acerca do pensamento geográfico: elementos para análise. Geografia Ensino \& Pesquisa, v. 17, n. 3 p.64-78, set./dez. 2013.

RAFFESTIN, Claude. Por uma geografia do poder. São Paulo: Ática, 1993.

RATZEL, Friedrich. O SOLO, A sociedade e O Estado. Revista do Departamento de Geografia, V. 2, p. 93-101. 2012.

SANTOS, Milton. Metamorfoses do espaço habitado. Paulo: Hucitec, 1988. 